\title{
TOWARDS A WORKPLACE CONDUCIVE TO THE CAREER ADVANCEMENT OF WOMEN
}

\section{Authors:}

Karen Lewis-Enright ${ }^{1}$

Anne Crafford ${ }^{1}$

Freddie Crous $^{1}$

\section{Affiliations:}

${ }^{1}$ Department of Industrial Psychology and People

Management, University

of Johannesburg,

South Africa

\section{Correspondence to: \\ Freddie Crous}

e-mail:

fcrous@uj.ac.za

\section{Postal address:}

Department of Human Resource Management,

University of

Johannesburg, PO Box 524

Auckland Park, Gauteng,

2000, South Africa

\section{Keywords:}

career advancement;

women and work;

workplace design:

leadership; inquiry

workshop

\section{Dates:}

Received: 03 Feb. 2009

Accepted: 08 May 2009

Published: 13 Aug. 2009

How to cite this article: Lewis-Enright, K., Crafford, A., \& Crous, F. (2009). Towards a workplace conducive to the career advancement of women. SA Journal of Industrial Psychology/SA Tydskrif vir Bedryfsielkunde, 35(1), Art. \#832, 9 pages. DOI: 10.4102/sajip.v35i1. 832

This article is available at: http://www.sajip.co.za

(C) 2009. The Authors. Licensee: OpenJournals Publishing. This work is licensed under the Creative Commons Attribution License.

\section{ABSTRACT}

The aim of this study was to start designing a workplace conducive to women's career advancement. Appreciative inquiry was selected as an appropriate methodology, given the slow progress that has been made in addressing gender equality at work. Seventeen men and women working in the finance division of a large organisation were invited to participate in an appreciative inquiry workshop. This was followed by interviews with four leadership team members. While no original ideas or solutions emerged from the interventions, participants of the appreciative inquiry process demonstrated a shift in thinking, more positive emotional responses, a shared vision for the future and improved willingness to assume accountability for change.

\section{INTRODUCTION}

A recent article in the Pretoria News entitled Women still lag far behind men in the workplace (Bolowana, 2005) highlights that, despite progressive legislation and aggressive organisational policies aimed at integrating women into senior management structures, little progress has been made.

In South Africa, statistics show that although women make up 52\% of the adult population, and have a $41 \%$ representation in the workforce, they hold a relatively small percentage of influential positions. Only $7 \%$ of South African directors are female, $3 \%$ of chairs of boards are female, and $2 \%$ of CEOs are female. In response to these statistics, influential business woman and CEO of Transnet, Maria Ramos, stated that 'SA cannot reach its full economic potential if not all avenues of talent are explored' (Women in Business Census 2004, 2004).

This situation is not unique to South Africa, however, as a global historical overview of women in management shows that, despite almost 30 years of equality legislation in western society, women managers are still under-represented in the workplace. The majority of women still tend to fulfil typically 'female' jobs (clerical, personal services and sales) and women are still paid less than their male counterparts (MacDonald, 2004).

Even though gender equality issues have formed part of legislative and social discourse in South Africa for at least the past 10 years, and even longer internationally, it is clear that society has yet to achieve parity in terms of adequate female representation in organisational management structures. Former South African president, Thabo Mbeki, while commending the work of the Commission on Gender Equality, commented that 'society still lags far behind in terms of actual implementation, particularly in mainstreaming gender issues' (Freeman, 2003).

Researchers and theorists have hypothesised on the reasons why women are under-represented in top positions despite factors such as legislation and a societal drive for the promotion of equal opportunity and the acceptance of difference. Although they are no longer required to resign from work on account of marriage and pregnancy, women are generally expected to fulfil homemaker roles; a situation which makes it difficult to maintain a career (MacDonald, 2004). This idea is verified by the findings of Rowe and Crafford (2003), who use the technique of imaginisation to compare women in their gender study to the story of Cinderella. In the fairy tale, Cinderella was not invited to the ball because of her status as 'maid'. Similarly, women in South African society are still expected to maintain their domestic roles, often incongruent with the goals of management. In addition, the fact that women's bodies enable them to be childbearers places them in a position where they often have to choose between a career and motherhood.

In many dual-income families, social workers have found evidence of female overload, male intransigence, child neglect and relationship problems. This is because many women who work also take on traditional roles, including the full burden of domestic responsibilities. This unpaid work, including reproductive, domestic, care-giving and emotional roles, often goes unnoticed by their husbands and society in general (Kornbluh, 1991).

Women's own beliefs about what is expected of them may constitute a barrier. In her study of Korean women in the banking sector, Kim (2004) showed that female aspirations tend to focus on balance and security rather than on getting ahead. Granlese (2004) showed that, compared to men, female managers in the UK banking sector experience greater occupational pressures. Women in top management positions tend to have fewer children and are less likely to be married than men; a decision that is often later regretted. Those women who are married have concerns about earning more than their partners. These findings indicate that women feel pressurised by the gender role society expects them to fulfil and the conflicting responsibilities of work and home.

There are often psychological barriers at play for women in management (Commission on Gender Equity Gaps Conference, 2000). Poor self-esteem, personal inadequacy, reticence, the 'imposter' syndrome and fear of rejection are all factors that contribute to women not advancing to their full career potential (Garrun, 2004). In addition, younger women expecting to be stay-at-home mothers tend not to plan their careers as well as men do. A study by Shaw and Shapiro (1987) shows that a lack of career planning 
has resulted in many capable women taking on lower paid jobs, leading to job dissatisfaction and mismatched expectations. In addition, organisations have generally been unable to offer adequately flexible working conditions. Even organisations that support part-time work are unable to provide developmental opportunities or challenging career paths (Tomlinson, 2004).

It would appear as though the male model of career progression is most certainly still intact. This model emphasises that to show commitment to the organisation and prove one's worthiness of a senior role, a manager needs to work long hours. This excludes many working mothers and married women with domestic responsibilities from the race to the top. Some men are also engaging in a subtle form of behaviour known as presenteeism, which reinforces this model of career progression and further excludes certain women. Presenteeism involves staying at the office for longer than necessary to complete the job so as to impress those in power (Doherty, 2004).

In addition, organisations may support a particular gender culture which men often accept as the norm, but which may make it difficult for women to achieve their potential in the workplace. Maddock and Parkin (1994) have identified seven gender cultures that may be found in organisations. In the gentlemen's club, women are seen as mothers and homemakers, while men are the breadwinners. Women in this type of organisation are generally low-paid, unskilled workers and will never advance to senior ranks. The barrack yard culture is operant when the boss bullies staff and subordinates all marginalised groups, including women. When men build relationships on the basis of common interests such as sport and sexual innuendo forms part of everyday conversation, a locker room culture is operant. In a gender-blind culture, women are treated in the same way as men and a level playing field is assumed despite the different needs and experiences of individuals. The smart macho culture creates enormous pressure to reach performance targets and budgets. The environment is extremely competitive and those who work at different paces, irrespective of their gender, are discriminated against. A new breed of politically correct men has emerged in the paying lip-service culture. These bosses are well-versed in feminism and proclaim a belief in equal opportunity. However, they do little to develop previously disadvantaged groups and do not allow these individuals to find their own voices, but rather speak on their behalf. In a culture where women are gatekeepers, women, both inside and outside the organisation, exclude other women from entering the ranks of power. These women benefit from the status quo and their self-esteem may be linked to enforcing tradition.

In Rowe and Crafford's (2003) imaginisation exercise, the relationship between Cinderella's stepsisters and mother was used as a metaphor for the poor support structures women have in business. Initially the women appear to support one another. However, as soon as a competitive element is introduced, their relationship deteriorates to one of petty fighting. Similarly, in business, women often have only surface level connections, which break down easily in the face of adversity. There is not a critical mass of women to form strong, supportive bonds. This is exacerbated by inadequate networking. Female managers tend to profile themselves poorly, underplaying their achievements and avoiding workplace politics. In order to get promoted or to be recognised in business, networking is critical. Cinderella won the prince over and got what she wanted by utilising the short time she had with him to profile herself adequately.

Despite these numerous societal, organisational and personal barriers, women in management still aspire to top jobs almost as much as their male counterparts do. Research appears to support the notion that it is in an organisation's interest to open up career paths for women and to help them achieve their aspirations. This is demonstrated in a recent study by the USA-based organisation Catalyst, where a link between gender diversity on management teams and financial performance was found. Those companies with a higher representation of women on their management teams showed better financial performance in terms of Return on Equity (ROE) and Total Return to Shareholders (TRS) than companies with lower representation. These results are partly explained by group diversity theory, which states that diverse groups tend to make more innovative decisions than homogenous groups if properly managed. In addition, organisations with female representation on their management teams will be better able to tap into the market of women who are making and influencing purchasing decisions. This is because they are more likely to produce products and services that appeal to all customers (Catalyst, 2004). HIRS, a South African organisation focused on empowering women in the workplace, believes that female managers take a different approach to management than men. Their approach can result in collegial workplaces, more consultative decision making, collaboration and a greater emphasis on personal values in the workplace (Garrun, 2004).

It is clear that organisations need to change their cultures and retention strategies so that they are able to overcome some of the barriers that women face and are better able to tap into the pool of available female talent. Gender equality is not simply about social justice, but is a critical source of competitive advantage for companies.

Several tentative solutions have been proffered, and implemented to some extent, to address the issues. At a societal level, a critical mass of female representation is important. Equal employment legislation (for example, South Africa's Basic Conditions of Employment Act and Employment Equity Act) is required to ensure that women have recourse to assistance when they are discriminated against and that organisations are required to meet specific targets (Commission on Gender Equity Gaps Conference, 2000). However, legislation in itself is not enough. Doherty (2004) highlights that there are typically two approaches to implementing gender equity in the workplace. The first approach, employment equity, promotes gender-blindness, which assumes that men and women are the same and have similar needs. This model ignores the specific challenges that face women in the workplace. The second approach, diversity management, focuses on the very different needs of women and ensures that these are protected. This model can backfire if men feel resentful of the preferential treatment received by their female colleagues. While neither of these approaches is adequate as a stand-alone solution, both are required if women are to feel equal, accommodated and valued (Doherty, 2004).

At an organisational level, several strategies have been proposed, including promoting women to positions of leadership, thus making them more visible (Rao \& Stuart, 1999), creating cultures in mainstream organisations that are more acceptable to women, offering flexible working conditions and acknowledging domestic responsibilities (Pile, 20054), and ensuring that men are part of the gender debate by providing gender sensitisation training to them (Rao \& Stuart, 1999; Sweetman, 2001).

On an individual level, women are encouraged to network with other women (Sweetman, 2001), plan their careers in advance (Shaw \& Shapiro, 1987) and ensure that, in their role as mothers, they sensitise their children to gender issues (Commission on Gender Equity Gaps Conference, 2000).

Despite numerous studies that have clarified the issues women face in the workplace, as well as extensive research into potential solutions for addressing these issues, the pace of change has been slow. It is my contention that this may be the result of the choice of methodology utilised to effect change. In my experience, organisational development interventions usually include experts spending time with management structures in order to understand the business problem, design an appropriate intervention, and then implement the solution. In some cases the degree of change is measured ('as-is' vs. 'to-be' states). Academic research about gender issues is also problem- or solution- 
oriented and focuses on gathering information, understanding it and providing new perspectives that may facilitate change. Both approaches adhere to a typical problem-solving framework:

- There is a felt need and identification of a problem;

- Causes are analysed;

- Possible solutions are proposed; and

- Actions are planned.

The underlying assumption is that organising is a problem to be solved and can be classified as deficit thinking (Hammond \& Royal, 1998).

However, seeing the issues faced by women in the workplace as a problem to be solved may have reduced the possibility of generating new theory or promoting positive action. This has brought research efforts and business interventions to a stalemate, where the topic is greeted with cynicism, few new ideas emerge and little positive action takes place. Evidently, there is a need to explore fresh techniques for addressing the topic of women advancing in the workplace.

Appreciative Inquiry, an organisational development approach introduced by Cooperrider and associates in the 1980s, offers an alternative methodology. The approach focuses on what the group ultimately wants (possibility thinking), rather than what stands in the way of what they want (deficit thinking). Appreciative Inquiry is defined as the search for knowledge and the theory of intentional collective action to help evolve the vision and will of a group (Busche, 1995). It is based on the hypothesis that social forms will always progress towards images that are affirming and life-giving. Appreciative Inquiry incorporates the following (Hammond \& Royal, 1998):

- Appreciating the best of what is;

- Envisioning what might be; and

- Dialoguing what should be.

For this reason, Appreciative Inquiry was selected as an appropriate methodology for designing a workplace in which women can win.

\section{RESEARCH DESIGN}

Appreciative Inquiry, as a contemporary action research methodology, focuses on changing how people think rather than what they do. It is based on the socio-rationalist paradigm, which holds that reality is a product of the present, open to continuous reconstruction. The contention of this worldview is that social order is fundamentally unstable, and is capable of infinite variations through the connection of ideas and action (Ludema, 2001).

Appreciative Inquiry is founded on eight principles (Whitney \& Trosten-Bloom, 2003):

- Constructionist principle: what we know and what we do are closely interwoven. There are no empirical truths out there to discover.

- Simultaneity principle: the act of observing a phenomenon changes it. By focusing on women's issues and possibilities for women, the participants are automatically conscientised.

- Poetic principle: the language that women use to describe themselves and their stories has an impact on how they think and behave.

- Anticipatory principle: the future is made, not predicted. What we do today is guided by an image of the future and influences that future.

- Positive principle: momentum and sustainable change requires social bonding. Positive participation is critical in bringing about social change.

- Wholeness principle: the experience of wholeness brings out the best in people, relationships, communities and organisations. Wholeness is never a singular story but a compilation of multiple stories, shared and woven together by the many people involved.
- Enactment principle: the observation that acting 'as if' is selffulfilling. Transformation occurs by acting out in the present what we most desire in the future.

- Free choice principle: people and organisations thrive when people are free to choose the nature and extent of their contribution. Allowing people to self-select their engagement and focus on their own interests as they get involved liberates both personal and organisational power.

In a typical Appreciative Inquiry intervention, specific phases are followed (Cooperrider \& Whitney, 2001). These include:

- Discovery: the process of uncovering the positive and understanding what is good about the current system;

- Dreaming is the process of stating an ideal and imagining what could be;

- Design is the process of coming up with provocative propositions of what should be, based on what is and what could be; and

- The Destiny stage gives participants an opportunity to codevelop action plans.

A recent meta-analysis of 20 Appreciative Inquiry case studies showed that this technique is most successful as a transformational tool when transformation is associated with changing how people think rather than what they do. According to this research, the most important step is the Design stage, where participants create provocative propositions. In addition, when the Destiny stage is characterised by open-endedness, rather than detailed project plans, the participants are more likely to nurture improvised action. The momentum for change and long-term sustainability increases when action planning and progress monitoring are abandoned. People should be compelled to find ways of transforming their situations themselves, rather than relying on a central project management function (Busche \& Khamisa, 2004). This was noted in the design of the intervention, and practically meant that the bulk of the time in the Appreciative Inquiry intervention was spent on creating provocative propositions and driving towards a selfreflective approach to change.

The present study was conducted in the finance division of a large financial institution. There are approximately 260 employees in the business unit and there is female representation at all levels. The head of the business unit encouraged the study, since he believes there is a need to investigate how a more female-friendly workplace could be designed. It seems that many talented women leave the business unit after they have had children.

A purposive sampling technique was used for this study to ensure that all participants were selected to participate because they possessed characteristics of interest to the study (Silverman, 2000). Members of the transformation committee, who represent all departments within the business unit, were asked to participate in a half-day Appreciative Inquiry workshop and to recommend individuals from their business units who would be able to add value in the design of a workplace where women could win. It was suggested that both males and females be included in the workshop, in line with the literature findings that male participation in the process is critical (Rao \& Stuart, 1999; Sweetman, 2001). An attempt was made to include individuals with and without families. The workshop was positioned as academic research, but was also contextualised as a way for the business unit to address gender-related issues using a different, participative and positively focused technique to gather data and propose solutions.

Altogether, 17 participants attended the workshop and there was representation from all departments. Six males and 11 females participated from all levels of the organisation, including five non-managers, eight junior managers and four senior managers/directors. After the workshop, findings were collated and circulated to the participants for commentary. 
TABLE 1

Paired Interview

\section{INTERVIEW QUESTIONS}

Tell me about a peak experience or high point in your professional life, a time when you felt most alive, engaged or really proud of yourself or your work. What was it about the situation, organisation or leadership that allowed this peak experience to emerge? Tell me your story.

Tell me about your beginnings at the organisation. What most attracted you to work here in the first place? Once hired, what were your initial positive impressions? Describe your earliest positive experiences with the organisation and how these reinforced your initial sense that this is a great place to work.

Describe a time when you worked on a team that benefited from diversity. How do we learn about each other's unique differences and gifts? What was special about what this team achieved?

Tell me about a time when you have been involved in a positive, effective, life-affirming working relationship with someone of the opposite gender. How did the relationship get started?

Think of another business/company that you admire.... you could know the business well or have just heard of it... it could be the corner grocery store or an internationally recognised organisation. What in your experience made this organisation best in class, particularly in terms of dealing with gender diversity? What do they do that we could learn to do better?

Why would women want to work at the organisation?

What is it about the organisation that best supports you in creating work-life/family balance?

Thinking about the organisation, what one thing could be done that would help create a better work-life/family balance?

Recall a time when you worked with a woman you considered an inspirational leader. Describe the situation. What made it inspirational for you? What did she do that inspired you? What could we do to foster winning teams/gender relations at work at an even higher, more consistent level, throughout the organisation?

What do you see today (not future possibilities but something that is beginning to happen now) that gives you hope for the future of women in the workplace? You could consider this globally or look at your own experience. It could have to do with personal, social, work or political events.

Interview Summary (To be completed by each interviewer). What were the best stories/quotes that you heard during the interview?

TABLE 2

Summary of themes emerging from the Discovery Stage

\section{EXPLANATION}

If she can do it, so can

Quality not quantity

Respect

Freedom of expression

Leading by example

Taking ownership

Participants noted that there are many fair, professional and competent women leaders who are already an example to their peers and subordinates. There are also more women filling influential positions now, both in the business unit and more broadly in society (e.g. our deputy president). Some women also appear to get their work-life balance right. Obtaining work-life balance is a real possibility if the correct support and reporting structures are in place in the organisation and if the culture supports a family orientation and discourages working unnecessary overtime. Some managers have already achieved this in their teams.

Many workshop participants had been in an affirming, positive working relationship with a member of the opposite sex and recalled how this interaction led to greater productivity and mutual trust.

It is important to appreciate each person's unique perspective and to value all employees, regardless of their choices and the role that their careers play in their lives. This applies equally to men who would like to spend more time with their families and to women who are prepared to make the significant time commitment required to get to the top.

All leaders should show exemplary behaviour as it relates to gender issues. This includes listening and understanding, being sincere and positive, supporting and mentoring others, even (or especially) those different from themselves. Particular organisational and team attributes, such as the level of job security, medical aid benefit, insurance cover, counselling provided and the leave policy, will either detract from or promote a positive working environment for women. Women must not be victims, but should change their own situations through their attitudes, the good work that they consistently produce and by aiming to obtain the best education possible. Women should also try to take on all opportunities presented to them.

TABLE 3

Dreaming about a future state

\begin{tabular}{ll}
\hline IDEA & EXPLANATION \\
\hline Full female representation & $\begin{array}{l}\text { There will be a critical mass of women in management/leadership positions. Women in executive roles will be listened } \\
\text { to and respected by their male counterparts. } \\
\text { Women will not work because they have to bring in a second income, but because they want to work. This will result in } \\
\text { stiffer competition for positions, higher productivity and better quality work overall. } \\
\text { Equality will be part of life, a reality and an accepted norm. Diversity will no longer be a discussion point; it will simply be } \\
\text { part of our culture. The role of both genders will be acknowledged and appreciated. }\end{array}$ \\
There will be a greater sensitivity to family responsibilities for both genders.
\end{tabular}

TABLE 4

Designing the future using metaphors and provocative propositions

\begin{tabular}{ll}
\hline METAPHOR & PROVOCATIVE PROPOSITION \\
\hline Honeycomb & $\begin{array}{l}\text { Our success and strength is as a result of our bees who work in teams, support each other, benefit from strong leadership } \\
\text { and work hard, producing liquid gold. } \\
\text { Our organisation is a beacon of light, leading the way, bringing warmth, comfort and safety by growing and supporting our } \\
\text { plorence Nightingale }\end{array}$ \\
$\begin{array}{l}\text { Doves and jet engines are able to do the same thing in very different ways (fly). We have to appreciate what both bring: } \\
\text { 'together we are a more powerful force'. }\end{array}$
\end{tabular}


TABLE 5

Social architecture - principles, people and practices

\begin{tabular}{|c|c|}
\hline ARCHITECTURE & SUGGESTIONS \\
\hline Principles & $\begin{array}{ll}- & \text { Acceptance of diversity } \\
- & \text { Sharing of responsibilities } \\
\text { - } & \text { Embracing change } \\
\text { - } & \text { Natural empathy }\end{array}$ \\
\hline People & $\begin{array}{l}\text { Allow people to change their situation by focusing on their strengths and contribution to the overall success of the team (self-mastery) through } \\
\text { training, development, recognition, reward, common understanding, ownership and acceptance at both a team and individual level. }\end{array}$ \\
\hline Practices & $\begin{array}{ll}\text { - } \quad \text { Workshops and competitions to teach appropriate culture } \\
\text { - } \quad \text { Recruit employees that share our values } \\
\text { - } \quad \text { Provide growth opportunities }\end{array}$ \\
\hline
\end{tabular}

TABLE 6

Destiny stage: personal and organisational changes

\begin{tabular}{|c|c|}
\hline PERSONAL CHANGES & ORGANISATIONAL CHANGES \\
\hline $\begin{array}{l}\text { - Role modelling: be an example and give support to other women } \\
\text { - } \quad \text { Rersonal effort: education, getting excellent results } \\
\text { Encouragement: men to accept that women are valuable resources, people to } \\
\text { - work together, no victim mentality, be more empathetic to women's needs } \\
\text { Status quo: do nothing, as the playing field is already equal, women can do } \\
\text { whatever they want to do, grow all employees not just women, there do not appear } \\
\text { to be any barriers for women }\end{array}$ & $\begin{array}{l}\text { - Accommodating: understand the different role requirements that some } \\
\text { - } \quad \text { Opomen might have } \\
\text { positions, recognise women for their achievements, ensuring that actual } \\
\text { contribution rather than perception is rewarded, hire more women into } \\
\text { senior positions/promote women } \\
\text { - Support: provide mentorship to women to ensure they succeed, set up } \\
\text { deliberate support networks } \\
\text { - Culture: ensure that gender-biased language is not accepted, promote } \\
\text { working in teams of equals } \\
\text { Training: educate staff about gender issues }\end{array}$ \\
\hline
\end{tabular}

TABLE 7

Spontaneous participant responses

\section{PARTICIPANT RESPONSES}

'I enjoyed the workshop and was interested and pleasantly surprised by the opinions and suggestions that were expressed. It is rewarding and positively affirming to realise that there are others with a similar outlook on many of the aspects of work and home life encountered by women' (ref. AP10)

'....best of luck with... driving towards some outcome within this rather sensitive area of today's corporate life' (ref. AP16)

'Thanks for inviting me. I really learned a lot' (ref. AP15)

'I didn't realise before that the jokes we [men] make about women were having any impact' (ref. AP11)

TABLE 8

Interviews with leadership

\section{INTERVIEW QUESTIONS}

Describe a working environment in which everyone can win

Have you got any ideas that you would like to add to the findings/elaborate on?

Do you have any comment on the process?

What are your thoughts on the workshop output?

Is this what you would have expected?

Is there anything missing?

Can the results be applied practically?

What, in your mind, is/are the immediate next step(s)?

Should this be an initiative in this business unit? How should it be championed?

Because of the length of time that the workshop took, there was concern that directors with decision-making power would not be in a position to attend the full session. To accommodate the views of these individuals, semi-structured in-depth interviews were conducted with four directors. Interviews are defined as two individuals meeting for the purpose of sharing information through questions and responses in order to construct a joint understanding of a particular topic (Esterberg, 2002). The interviews included a presentation of the findings of the Appreciative Inquiry workshop, open-ended questions to gather the leaders' personal views regarding the design of a workplace more conducive to women's career success, and a discussion where decision-makers were asked to outline a potential way forward for the business unit. During the interviews, reflection and probing were used to ensure a common understanding of the conversation content. Interview data was then transcribed.

All sets of data derived from the workshop and the content of the interviews were then analysed using the general qualitative
TABLE 9

Issues facing women as identified by interviewees

\begin{tabular}{|c|c|}
\hline THEME & SUPPORTING DATA \\
\hline $\begin{array}{l}\text { Assumptions are made } \\
\text { about the nature of } \\
\text { women }\end{array}$ & $\begin{array}{l}\text { - 'Assertive women are seen as aggressive' } \\
\text { (ref. IP1) } \\
\text { 'If you don't have a specific type of personality, } \\
\text { you will feel prejudiced as a woman' (ref. IP2) }\end{array}$ \\
\hline $\begin{array}{l}\text { Barriers women have to } \\
\text { deal with on a personal } \\
\text { level }\end{array}$ & $\begin{array}{l}\text { - 'People say things about women, but you have } \\
\text { to be driven to work harder' (ref. IP2) } \\
\text { 'Human dignity issues still exist, especially in } \\
\text { lower ranks of organisation' (ref. IP3) } \\
\text { 'Of course a boy's club exists, and we must } \\
\text { break it, but questioning why it is there just } \\
\text { creates resistance' (ref. IP1) } \\
\text { 'Women are their own worst enemies' (ref. } \\
\text { IP1) }\end{array}$ \\
\hline $\begin{array}{l}\text { Poor representation of } \\
\text { women in management }\end{array}$ & $\begin{array}{l}\text { - 'There are no examples of women in top } \\
\text { management' (ref. IP4) } \\
\text { 'Men still get given the roles that put them in } \\
\text { the limelight' (ref. IP3) }\end{array}$ \\
\hline $\begin{array}{l}\text { Potential conflict for } \\
\text { working women with } \\
\text { families }\end{array}$ & $\begin{array}{l}\text { - 'Women need to understand that with seniority } \\
\text { comes a time commitment so if you decide to } \\
\text { work half-day you can't expect to progress as } \\
\text { fast' (ref. IP3) } \\
\text { 'Women feel guilty because of time } \\
\text { commitment at work and then losing out on } \\
\text { family time' (ref. IP2) } \\
\text { 'Everyone must be made to feel valued, } \\
\text { irrespective of their choices and the role that } \\
\text { their careers play in their lives' (ref. IP4) } \\
\text { 'Women have two jobs' (ref. IP3) } \\
\text { 'Other than the mother/child situation I don't } \\
\text { see a need for different treatment between } \\
\text { men and women' (ref. IP1) }\end{array}$ \\
\hline
\end{tabular}


TABLE 10

Solutions proposed by Interviewees

\begin{tabular}{|c|c|}
\hline PROPOSED SOLUTION & SUPPORTING DATA \\
\hline $\begin{array}{l}\text { Set organisation policy to attract more women into } \\
\text { the organisation }\end{array}$ & $\begin{array}{l}\text { - } \quad \text { 'Need to set targets' (ref. IP1) } \\
\quad \quad \text { 'Need to create a pull from the organisation to help women' (ref. IP3) } \\
\text {-Recognise that our biggest employment equity lever is black African women' (ref. IP3) }\end{array}$ \\
\hline Create opportunities for women & $\begin{array}{l}\text { - 'Need to promote/ recruit women who are ready to be in top management' (ref. IP4) } \\
\text {-We've got to trust that women can do the job' (ref. IP3) }\end{array}$ \\
\hline Create a supportive infrastructure & $\begin{array}{l}\text { - } \quad \text { 'Women should listen to other women who have "made it" to understand their sacrifices and regrets' (ref. IP2) } \\
\quad \text { - 'Mentorship is key' (ref. IP2) } \\
\text { - } \quad \text { 'While a father's a role at home is important, it is impractical for our organisation to address this unless other companies } \\
\text { - do the same. This is not in our immediate interest' (ref. IP1) } \\
\text {-Women must network' (ref. IP1) }\end{array}$ \\
\hline Create a more female-friendly culture & $\begin{array}{l}\text { - 'Worldviews of white male executives have to be changed; they need to see that women can be breadwinners and } \\
\text { are not always just housewives' (ref. IP3) } \\
\text { - 'Inappropriate behaviour will not be accepted' (ref. IP1) } \\
\text { - } \quad \text { 'Exploit our differences' (ref. IP4) } \\
\text { 'I have never felt personally prejudiced as a women at work' (ref. IP2) }\end{array}$ \\
\hline Educate future generations & $\begin{array}{l}\text { - } \quad \text { 'Children need to have access to both their parents' (ref. IP2) } \\
\text { 'Children should be encouraged to master activities that they enjoy irrespective of the possible inherent gender bias. } \\
\text { [This will] help them understand the role they can play in the workplace later, irrespective of their gender' (ref. IP4) }\end{array}$ \\
\hline
\end{tabular}

phases identified by Baptiste (2001): (1) defining the analysis; (2) classifying the data; and (3) making connections between data. This approach was chosen because it provides phases common to most qualitative data analysis techniques, thus accommodating inexperienced researchers. The focus of the approach is to identify the key questions that a responsible analyst would pose during the various phases of data analysis.

\section{RESULTS \\ Appreciative Inquiry workshop}

Prior to the workshop an invitation was sent to participants positioning the concept of 'women winning in the workplace', outlining the purpose of the session and requesting their time for the event. A participant guide containing a summary of the literature review, an overview of the Appreciative Inquiry process, interview questions and space for participants to take notes was prepared.

On the day of the workshop, the facilitator, who is an expert in the use of the Appreciative Inquiry technique, was introduced. My intentions for the study and role as an observer in the workshop were also explained. Thereafter an overview of the study was presented and the Appreciative Inquiry technique was briefly summarised for participants. Each participant then received a participant guide.

The first stage of the Appreciative Inquiry process, Discovery, took the form of interviews, where participants were split into pairs and coached on the use of semi-structured interviews to gather data from their partners. The goal of this appreciative interview was to explore the participant's peak experiences (Cooperrider \& Whitney, 2001). The interview questions, adapted from the Encyclopedia of Positive Questions (Cooperrider, Whitney \& Trosten-Bloom, 2001), are outlined in the table below.

As a larger group, participants reflected briefly on the paired interviews. Their comments made mention of a range of emotions and experiences, such as feeling that the process was scary, informative, energising, a good opportunity to reflect and that it was difficult not to be negative. Participants were placed in three smaller groups and asked to summarise the key themes emerging from the interviews. The broader group then voted to determine the most important themes. These are outlined in Table 2 below.

In the Dreaming stage, participants were asked to work in three groups to identify an ideal state for the organisation, by answering a question related to the future: 'It is 10 years from now and the organisation is voted the best company for women

1. Quotes from participants have been catalogued as follows: ref. AP1 to 17 refers to Appreciative Inquiry Participants; ref. IP1 to 4 refers to Interview Participants. Information documented by Appreciative Inquiry workshop groups has been presented collectively rather than attributed to a particular individual. to work for. Why? What does it look like?' The results of this exercise are summarised in Table 3.

The Design process involved the three groups creating metaphors to explain their future ideal and verbalising a provocative proposition which could move the organisation from its 'as-is' state to the future ideal. Table 4 below outlines the metaphors and the provocative propositions.

To complete the Design stage, participants defined the social architecture required to achieve the desired future state. These included principles, people and practices required to move towards the ideal and these are outlined below.

The Destiny stage enabled individuals to look at what they would personally do differently to ensure women could win in the workplace as well as what the organisation should do differently in the future. Refer to Table 6 below for details.

Following the Appreciative Inquiry workshop, findings were collated and circulated to all participants for additional comment and input. While none of the candidates changed any of the content, some interesting remarks emerged spontaneously. These are documented in the table below.

\section{Interviews}

The interviews with directors were semi-structured. Directors were asked to describe a working environment in which women could win. Reflection and probing were used to elicit further input. Once this avenue of questioning was exhausted, the Appreciative Inquiry workshop process and results were presented. The directors were asked to comment on both the process and the findings as well as to provide input on what should be done to practically address the issue of women winning in the workplace. The detailed interview schedule can be found in Table 8 .

Interview questions were positively framed and appreciative in nature. However, the way in which the questions were structured, as well the expectations of the participants due to their research exposure and their seniority in the organisation, did not lend itself to a story-telling approach or the co-creation of meaning. As a result, the interview approach and process was significantly different to the paired interviews that took place in the Appreciative Inquiry workshop.

Without prompting, and despite the appreciative nature of the interview question regarding women winning, all interview candidates immediately focused on the issues that women face in the workplace. Key highlights are presented in the table below.

Interviewees also focused on utilising the advantages of having women in the organisation. These advantages were identified as 
characteristics unique to women, which men were seen not to possess. These included women being more in touch with people ('women have a higher EQ' (ref. IP1); 'women are intuitive' (ref. IP2)); and women being able to handle some situations more effectively than men ('women are better able to understand grey areas and not be black and white about everything' (ref. IP1); 'women are better negotiators' (ref IP2)).

Practical solutions proposed as a way forward by interview candidates are summarised in Table 10.

\section{Comparing Appreciative Inquiry and interviews}

While it was initially disappointing to have to use separate data-gathering techniques as a result of the lack of availability of senior decision-makers, this proved to be extremely valuable in hindsight as it provided an opportunity for the comparison of techniques. The data gathered in the Appreciative Inquiry workshop and the interviews were aligned with the findings in the literature, with no original ideas emerging from either technique. The key difference was found in the participants' emotional response to the data.

In the Appreciative Inquiry workshop participants dealt with various contentious issues in a positive, action-oriented manner, without spending time debating points of disagreement. The role of men was recognised as important in changing the status quo, especially with regards to the support men should be providing at home and the balance of life issues that affect family men. Gender-related bias in the workplace was addressed and owned ('no degradation [of women]' (ref. AP11; 'treat women in senior roles with respect' (ref. AP4)). Some participants held the view that women are already receiving equal treatment ('I believe the playing field is already equal. Women can be whoever and do whatever they want to' (ref. AP13); 'there do not appear to be any barriers for women' (ref. AP6)), but this did not stop them from actively participating in the workshop. Without consciously designing this into the Appreciative Inquiry workshop, different viewpoints were explored and participants were able to discuss others' perspectives without inhibiting the group's actionorientation or each individual's personal responsibility in changing the status quo.

In contrast, the interviews were fraught with clichés about the topic, as reflected in the literature: 'we must break [the boy's club]' (ref. IP1); 'women are their own worst enemies' (ref. IP1); 'women have two jobs' (ref. IP3); 'women must network' (ref. IP2); 'exploit our differences' (ref. IP1); 'assertive women are seen as aggressive' (ref. IP1). Contentious ideas were either avoided or handled in a defensive manner. Even when the topic was tackled directly, the idea of men playing a role at home was downplayed ('while a father's role at home is important, it is impractical for our organisation to address this unless other companies do the same. This is not in our immediate interest' (ref. IP1)). In addition, the negative roles that men could play in the workplace were emphasised (excluding women by participating in the 'boy's club'; indulging in sexually inappropriate behaviour). None of the interview candidates expressed an opinion about women already receiving equal treatment, even if they felt that this was the case. What came to the fore, without being questioned, was the underlying belief that women will always play the role of primary care-giver in a family: 'other than the mother/child situation I don't see a need for different treatment between men and women' (ref. IP1). The problems of overt gender bias in the workplace elicited an angry response from some participants: 'the worldviews of white male executives have to be changed; they need to see that women can be breadwinners and are not always just housewives' (ref. IP3). When pressed for solutions, interviewees were defensive and sometimes even cynical: 'I have never felt personally prejudiced as a woman at work' (ref. IP2); ' there is no point in analysing] why a boy's club exists' (ref. IP1). Interviewee comments on the results of the Appreciative Inquiry process showed that the organisation's leaders were non-committal about the technique: 'I can't really disagree with anything that's been said, but some of the data is a bit vague and unhelpful' (ref. IP1).

\section{Reflections on the process}

During the course of this study I was pregnant with and gave birth to my first child. Questions about the roles that men and women play in the running of a household, childcare and how these impact on one's career therefore became of personal interest. Having conducted a study of this nature, I felt more able to tackle some of the issues in advance, engage my partner in making difficult choices and to question the typical gender roles that are generally taken for granted. Being conscientised to the roles both genders need to play made a material difference to the types of solutions that were considered regarding the roles of raising a family and earning a living.

Another important note is that I have always been involved in large-scale organisational change management interventions. I was trained as a consultant in the problem-solving paradigm and usually approach workplace initiatives by gathering information about the 'as-is' situation, defining the 'to-be', performing a gap analysis, recommending an approach and then implementing the recommendations. The topic of women's advancement in the workplace had always plagued me as one of the notable failures of change management practitioners. Exposure to the Appreciative Inquiry technique highlighted the importance of defining a common vision of the future and involving stakeholders in designing solutions to achieve that vision. Although this terminology is used in traditional change management interventions, its practical application is quite different in Appreciative Inquiry, where the process is all about the participants, and management's agenda or view of a problem become secondary.

One of the strengths of this study was the opportunity for me to reflect on the contrasting responses that emerged from the different methodologies. Even though the interview questions were posed in an appreciative manner, they could not be compared to the Appreciative Inquiry workshop paired interviews in terms of structure and process. As a result, the content of the discussions was significantly different. While the Appreciative Inquiry interviews resulted in stories that created a deeper understanding of the other and a shared positive meaning, the data from the interviews with leaders was more negative and sometimes clichéd. It is possible that the interviews could have been designed on a more appreciative basis by focusing on shared storytelling, rather than on semi-structured questions. However, the process would need to be positioned differently, since the participants would have attached a specific meaning to an interview for academic research purposes and would have had definite expectations of how the process would unfold.

\section{DISCUSSION}

It is interesting to note that interviewees who did not participate in the Appreciative Inquiry workshop did not understand the process and shift in thinking that had taken place in the workshop participants. The data emerging from the intervention was regarded by the leadership who reviewed it as benign and not specifically value-adding. Yet the workshop participants had a completely different experience. The value of the workshop was not found in the generation of creative solutions, as no new ideas that had not already been presented in the literature emerged. The 'magic' of Appreciative Inquiry lay in the shift in thinking, the joint envisioning for the future, the participation of all stakeholders and the prioritisation process. The impact of the change was to some extent immediate. This is demonstrated in one of the participant's responses after the session, which constitutes a powerful self-reflection and an example of a change in thinking - the trademark of Appreciative Inquiry: 'I didn't realise before that the jokes we [men] make about women were having any impact' (ref. AP11). It was difficult to generate a common vision of the future in the interviews because a 
series of dichotomous views were presented and participants were not empowered to see the perspectives of others. The Appreciative Inquiry workshop created an opportunity for participants to make a mindset shift and view the world from another's perspective.

The Discovery stage of the Appreciative Inquiry workshop gave participants an opportunity to reflect on the positive aspects of the current situation at work and to use these ideas as a base for building the future. The content of these discussions became solution-focused immediately, with participants bearing testament to options that had worked for them in the past. Ideas that emerged are all reflected in the literature: mentorship (if she can do it, so can I; leadership); challenging the male model of career progression (quality not quantity); instilling a womanfriendly culture (respect; leadership); giving people a choice about the roles they take on (freedom of expression); instilling self-confidence in women (ownership). Even though no new solutions emerged, participants were able to acknowledge that, in their current context, there were positive factors that could be used to build towards a future ideal.

Without prompting, interviewees immediately reverted to a problem-oriented mindset. All the barriers to women's success in the workplace, as identified in the literature, emerged in some form. One reason for this could be that those interviewed are all well-versed on gender-related topics and were merely repeating what they had read or heard. Another hypothesis is that these are genuine problems that women face in the workplace. Either way, nothing new emerged from the interviews to assist in designing an ideal workplace for women. This corroborates my contention that a problem-solving approach merely results in reiterating the existing findings without addressing practical solutions.

The Dreaming stage of the Appreciative Inquiry workshop allowed participants to present a future ideal. Rather than seeing the gap between the 'as-is' and 'to-be' states, the process allowed people to visualise a future ideal, unfettered by current problems. The ideas that emerged were simple, and, in summary, amount to a requirement for gender equality at home and at work, as well as work-life balance for all. This is a succinct way of summarising the findings of years of research and clarifying what it is we are aiming towards in this field.

Candidates were not given a direct opportunity to express their future ideal in the interviews. This could have been construed as a very confrontational and personal question, especially in the context of such a sensitive topic. In a typical problemsolving approach, the future ideal is assumed and the focus is on removing the barriers to achieving what everyone wants.

During the Design stage of the Appreciative Inquiry workshop, participants were given an opportunity to create metaphors and provocative propositions to highlight their view of what the organisation should be aiming for. Beautiful imagery emerged. One of the groups compared the organisation to a honeycomb, highlighting the need for teamwork, support and strong delivery. The image of a honeycomb is female-friendly, since a swarm of bees is headed by a queen, a female leader. Another group saw the organisation becoming like Florence Nightingale, a female saviour of the disenfranchised. This image captures the idea that everyone belongs and that family is important. The third group used the joint image of a dove and a jet engine, thereby recognising the different approaches and strengths each of the genders employs to achieve the same goal (in this case, flying).

The final aspect of the Design stage is defining a new social architecture. The ideas that emerged here, in my view, were less captivating, as they were aligned to the stock-standard practices already proposed in the literature. This is congruent with the findings in the literature that provocative propositions are the most powerful and important component of successful Appreciative Inquiry workshops. What was important in this aspect of the Design process, however, was that participants designed and owned the solutions.

The Destiny stage of the Appreciative Inquiry workshop was of great interest because all the solutions proposed in the literature were mentioned. However, when candidates were asked to look at what they could personally change, the ideas presented were specific and action-oriented: 'get an education'; 'be a role model'; 'educate men'; and 'treat people with respect'. Throughout the process there was an implicit acknowledgement that individual action can change the status quo.

In the interviews it became evident that candidates did not design the future together, but merely commented on solutions from their own perspectives. Almost all of the solutions mentioned in the literature emerged, phrased as actions for the organisation (formulating policy to attract women, creating opportunities for women, creating a supportive infrastructure for women, creating a female-friendly culture). Two ideas from the literature that are not reflected in the interview data are that women should be encouraged to do more aggressive career planning from an early age and that men need to play an active role in gender issues. This emphasises the lack of individual accountability in addressing issues and a poor understanding that the broader social system maintains the status quo.

It is noteworthy that the emotional reaction of the interview candidates was completely different to that expressed by the workshop participants. Anger, defensiveness and avoidance, the exact emotions that can prevent us from becoming unstuck, were all expressed in the interviews. On the other hand, the Appreciative Inquiry workshop candidates were reflective, thankful and positive about the future, even though there were some fundamentally different views expressed in the session. The power of possibility thinking in Appreciative Inquiry, as compared to the deficit thinking in a typical problem-solving approach, is evident.

\section{Conclusion}

All of the problems and solutions presented in the literature review emerged during the course of the study. It is therefore clear that in the sphere of gender equity in the workplace, the slow pace of change is not the result of inaccurate information or a lack of ideas. The difficulty lies in the implementation of the ideas in a systemic fashion. This study shows that Appreciative Inquiry may be an effective technique for facilitating change in gender dynamics in this organisation. However, in order for the momentum created in the workshop to be maintained, additional workshops would be required, particularly with the leadership team. As a research technique in the field of women's careers and gender issues in the workplace, Appreciative Inquiry shows great potential for exposing issues in a nonconfrontational manner, encouraging a participative approach to solution-seeking, appreciating the current context and setting bold objectives for the future.

\section{REFERENCES}

Baptiste, I. (2001). Qualitative data analysis: Common phases, strategic differences. Retrieved February 28, 2005, from http://www.qualitative-research.net/fqs-texte/3-01/301baptiste-e.pdf.

Bolowana, A. (2005, February 15). Men still rule in workplace. Pretoria News.

Busche, G.R. (1995). Advances in appreciative inquiry as an organization development tool. Organisation Development Journal, 13(3), 14-22.

Busche, G.R., \& Khamisa, A. (2004). When is appreciative inquiry transformation? A meta-case analysis. Retrieved February 28, 2005, from http://www.gervaseushe.ca/aimeta.htm.

Catalyst. (2004). The bottom line: Connecting corporate performance and gender diversity. New York: Catalyst. 
Commission on Gender Equity Gaps Conference. (2000). Conference on gender and the private sector report. Braamfontein: CGE Head Office.

Cooperrider, D., \& Whitney, D. (2001). A positive revolution in change: Appreciative inquiry. In D. Cooperrider, P. Sorensen, T. Yaeger \& D. Whitney (Eds.), Appreciative inquiry: An emerging direction for organization development (pp. 125-160). Champaign: Stipes Publishing.

Cooperrider, D., Whitney, D., \& Trosten-Bloom, A. (2001). An encyclopedia of positive questions (vol 1): Using appreciative inquiry to bring out the best in your organization. New York: Lakeshore Communications.

Doherty, L. (2004). Work-life balance initiatives: Implications for women. Employee Relations, 26(4), 433-452.

Esterberg, K.G. (2002). Qualitative methods in social research. Boston: McGraw-Hill

Freeman, C. (2003, February 14). Gender equity: Struggle not over. BuaNews.

Garrun, T. (2004, July 19). Glass ceiling still intact. The Star, Workplace.

Granlese, J. (2004). Occupational pressures in banking: Gender differences. Women in Management Review, 19(4), 219-226.

Hammond, S.A., \& Royal, C. (1998). Lessons from the field: Applying appreciative inquiry. San Francisco: Thin Book Publishing Co.

Kim, N. (2004). Career success orientation of Korean women bank employees. Career Development International, 9(6), 595608.

Kornbluh, F. (1991). Women and work: An overview review. Off Our Backs, 21(5), 28-32.

Ludema, J.D. (2001). Appreciative inquiry: The power of the unconditional positive question. In P. Reason \& H. Bradbury (Eds.), Handbook of Action Research (pp. 189-199). London: Sage Publications.
MacDonald, I. (2004). Women in management: An historical perspective. Employee Relations, 26(3), 307-319.

Maddock, S., \& Parkin, D. (1994). Gender cultures: How they affect men and women at work. In M.J. Davidson \& J. Burke (Eds.), Women in Management: Current Research Issues (pp. 30-40). London: Paul Chapman Publishing.

Pile, J. (2004, April 30). SA's most powerful women in business. Financial Mail.

Rao, A., \& Stuart, R. (1999). Rethinking organisations: A feminist perspective. In C. Sweetman (Ed.), Gender in Development Organisations (pp. 10-16). Oxford: Oxfam.

Rowe, T., \& Crafford, A. (2003). A study of barriers to career advancement for professional women in investment banking. SA Journal of Human Resource Management, 1(2), 21-27.

Shaw, L.B., \& Shapiro, D. (1987). Women's work plans: Contrasting expectations and actual work experience. Monthly Labour Review, 110(11), 7-13.

Silverman, D. (2000). Doing qualitative research: A practical handbook. London: Sage.

Sweetman, C. (2001). Sitting on a rock: Men, socio-economic change, and development policy in Lesotho. In C. Sweetman (Ed.), Beyond Rhetoric: Men's Involvement in Gender and Development Policy and Practice (pp. 71-78). Oxford: Oxfam.

Tomlinson, J. (2004). Perceptions and negotiations of the business case for flexible careers and integration of parttime work. Women in Management Review, 19(8), 413-420.

Whitney, D. \& Trosten-Bloom, A. (2003). The power of appreciative inquiry: A practical guide to positive change. San Francisco: Berrett-Koehler.

Women in Business Census 2004. (2004). Retrieved February 28, 2005, from http://www.southafrica.info/pls/procs/iac. 